\title{
Is Alcohol More Dangerous Than Severe Acute Respiratory Syndrome Coronavirus 2 in Iran?
}

\author{
Gholamreza Farnoosh, PhD; Seyed Reza Hosseini Zijoud, PhD (1)
}

A ccording to official statistics released by the Iranian Ministry of Health, as of April 8, 2020, a total of 64586 people have contracted the coronavirus disease (COVID-19) and 3993 people have died. In other words, about $6.1 \%$ of patients diagnosed with COVID-19 have died in Iran. ${ }^{1}$

However, according to the same ministry announcement, as of March 31, 2020, 3117 poisonings (ages 4 to 72 years) were caused by alcohol consumption, which caused the death of 320 patients. The alcohol poisoning mortality rate is about $10.3 \%$. Also, about $2 \%$ (62 people) of alcohol poisoning cases lead to blindness or low vision, and about $9.1 \%$ (284 people) lead to kidney disease. ${ }^{2}$

Recent rumors in Iran about the positive effect of alcohol consumption on the prevention of severe acute respiratory syndrome coronavirus 2 (SARS-CoV-2) infection, and its treatment effects on people with COVID-19 led to a rise in alcohol consumption and poisoning.

In almost all 31 provinces of Iran, there have been reports of deaths from alcohol abuse. Hospital reports indicate that the number of alcohol poisoning cases in some cities has exceeded the number of patients with COVID-19. Also, medical officials have warned that the death cases from alcohol consumption in some cities have surpassed the death cases from COVID-19. ${ }^{3}$ All this while the consumption of alcohol and its derivatives in Iran as an Islamic country is prohibited by law and religion.

These people turn to alcohol consumption for internal disinfection of the body and to prevent infection from SARS-CoV-2. They have tried to drink or gargle alcohol. Meanwhile, instead of ethanol, which has no effect on fighting SARS-CoV-2, a group has drunk methanol, which is very toxic and dangerous. ${ }^{3}$

Some people believe that since SARS-CoV-2 is sensitive to alcohol used for hand and surface disinfection, the same effect happens inside the body with alcohol consumption, and that the alcohol acts as a disinfectant inside the body, although this is a wrong, unscientific, and unhealthy misconception.

Meanwhile, in recent days in Iran, some profiteers and fraudsters have changed the color of methanol and sold it in place of ethanol, and people who used to prepare ethanol for oral consumption have been victimized by buying methanol. ${ }^{3}$

The first warnings were given by Iranian health officials about the distribution of methanol on March 2, and it was described as a "big problem," but other officials ignored it. ${ }^{4}$ Judicial and police officials have claimed that rumors of alcohol consumption to disinfect the inside of the body for prevention of COVID-19 have spread on social media and caused a crisis.

The alcohol crisis began on the first day of 2 people being officially confirmed with COVID-19 in Qom City, Iran, on February 29, 2020..$^{5}$ The first thing that became scarce and expensive in the drugstores were alcohol pads, and when ethanol consumption was intensified to disinfect, the production of alcohol and alcohol-based disinfectants increased. Alcohol hoarding and rising alcohol prices (up to 5 times) were another problem. Therefore, the government zeroed the import tariff on alcohol, banned the export of alcohol, and sending it to other cities was also banned.

People were desperately looking for ethanol for disinfection uses, and some profiteers and fraudsters were using methods to change the color of methanol and sell it to people as ethanol. These events have made alcohol a rival to SARS-CoV-2 over the past 2 weeks, both regarding crisis and victimization.

Eating methanol has many side effects, such as dizziness, nausea, shortness of breath, abdominal pain, blurred vision, and blindness. Twenty-four hours after consumption of methanol and its breakdown in the liver, the patient will develop seizures and a heart attack. Those who survive such poisoning will likely endure kidney, liver, and vision problems for the rest of their lives. ${ }^{6}$ 
Iranian health officials have urged people not to pay attention to non-medical prescriptions on social media. People should buy alcohol from reputable places, such as pharmacies, and the alcohol of choice should be ethanol for disinfection of hands and surfaces. Physicians have also repeatedly stated in television programs that alcohol consumption has no effect on preventing COVID-19; however, its use is still a matter of concern in the wake of the COVID-19 crisis in Iran. In the midst of facing one deadly crisis with COVID19 , the Iranian people and health officials are also struggling to fight another - alcohol abuse by some people.

\section{About the Authors}

Applied Biotechnology Research Center, Baqiyatallah University of Medical Sciences, Tehran, Iran (Farnoosh) and Clinical Research Development Unit, Imam Hossein Hospital, Shahid Beheshti University of Medical Sciences, Tehran, Iran (Hosseini Zijoud).

Correspondence and reprint requests to Seyed Reza Hosseini Zijoud, Clinical Research Development Unit, Imam Hossein Hospital, Madani Street, Tehran, Iran 1617763141 (e-mail: Hosseini7sr@gmail.com).

\section{Conflict of Interest Statement}

The authors have no conflicts of interest to declare.

\section{Authors' Contributions}

SRHZ and GF both conceptualized this letter. SRHZ drafted the first version of the manuscript. GF critically reviewed the manuscript and provided detailed suggestions and revisions. Both authors read and approved the final manuscript as submitted. The authors are accountable for all aspects of the work in ensuring that questions related to the accuracy or integrity of any part of the work are appropriately investigated and resolved.

\section{REFERENCES}

1. Worldometer. Coronavirus, Iran. Updated 2020. https://www.worldo meters.info/coronavirus/country/iran/. Accessed April 4, 2020.

2. Anadolu Agency. Iran: death toll from tainted alcohol rises to 255. March 25, 2020. https://www.aa.com.tr/en/latest-on-coronavirus-outbreak/iran-deathtoll-from-tainted-alcohol-rises-to-255/1779301. Accessed April 4, 2020.

3. IRNA. Bitter end of corona treatment with alcohol. March 12, 2020. https://www.irna.ir/news/83709252/. Accessed April 4, 2020.

4. Mizan Online. Industrial alcohol poisoning warning (methanol). March 19, 2015. https://www.mizanonline.com/fa/news/604319/. Accessed April 4, 2020.

5. Farnoosh G, Alishiri G, Hosseini Zijoud SR, et al. Understanding the severe acute respiratory syndrome coronavirus 2 (SARS- $\mathrm{CoV}-2$ ) and coronavirus disease (COVID-19) based on available evidence - a narrative review. J Mil Med. 2020;22(1):1-11.

6. Holt NR, Nickson CP. Severe methanol poisoning with neurological sequelae: implications for diagnosis and management. Intern Med J. 2018; 48(3):335-339. 